NBER WORKING PAPER SERIES

\title{
THE EFFECT OF UNCERTAINTY \\ ON INVESTMENT: SOME \\ STYLIZED FACTS
}

John V. Leahy

Toni M. Whited

Working Paper No. 4986

\section{NATIONAL BUREAU OF ECONOMIC RESEARCH 1050 Massachusetts Avenue \\ Cambridge, MA 02138 \\ January 1995}

We would like to thank two anonymous referees, Andy Abel, Ben Bernanke, Giuseppe Bertola, Tim Erickson, Paul Evans, Michel Habib, Greg Mankiw, Masao Ogaki, and Sergio Rebelo for helpful comments and discussions. We are also grateful to Joanne Doyle for providing us with the BLS data. This paper is part of NBER's research program in Economic Fluctuations. Any opinions expressed are those of the authors and not those of the National Bureau of Economic Research.

(ㄷ) 1994 by John V. Leahy and Toni M. Whited. All rights reserved. Short sections of text, not to exceed two paragraphs, may be quoted without explicit permission provided that full credit, including $\odot$ notice, is given to the source. 


\title{
THE EFFECT OF UNCERTAINTY \\ ON INVESTMENT: SOME \\ STYLIZED FACTS
}

\begin{abstract}
The theoretical relationship between investment and uncertainty is ambiguous. This paper briefly surveys the insights that theory has to offer and then runs a series of simple tests aimed at evaluating the empirical significance of various theoretical effects. Our results from a panel of U.S. manufacturing firms indicate a negative effect of uncertainty on investment consistent with theories of irreversible investment. We find no evidence for a positive effect via the channel of the convexity of the marginal product of capital, and we find no evidence for the presence of a CAPM-based effect of risk.
\end{abstract}

John V. Leahy

Department of Economics

Harvard University

Cambridge, MA 02138

and NBER
Toni M. Whited

Department of Economics

University of Delaware

Newark, DE 19716 


\section{Introduction}

Economic theory has much to say about the relationship between uncertainty and investment. Taken as a whole, however, what theory has to say is ambiguous. Different theories emphasize different channels, some pointing to a positive relationship and some to a negative relationship. Given this ambiguity, it is surprising that little empirical work has been done aimed at signing the effect of uncertainty on investment and sorting out the relative importance of these various channels. The goal of this paper is to establish some stylized facts concerning this relationship and then to evaluate the various theories in light of these results.

We can classify theories of investment under uncertainty along two dimensions. First, we can distinguish between theories that look at the firm in isolation and emphasize the variance of some aspect of the firm's environment and theories that look at the firm in relation to other firms and emphasize covariances in the returns between investment projects. In the former case uncertainty itself matters for investment, whereas in the latter case uncertainty matters only in so far as it affects covariances. Second, we can distinguish between theories that predict that the marginal revenue product of capital is convex in some random variable and theories that predict that the marginal revenue product of capital is concave. In the former case an increase in the variance of the random variable will increase the incentive to invest, whereas in the latter it will discourage investment.

The role of covariances is explored by Craine (1988) in a version of the capital asset pricing model (CAPM). According to the CAPM the required rate of return on an investment should be positively related to that investment's risk, which, in turn, is measured by the covariance of its returns with the market as a whole. An increase in the covariance should increase the riskiness of investment, increasing the required rate of return and reducing the desired level of the capital stock. The CAPM therefore predicts that the greater the covariance in returns the less the incentive to invest. 
Models of individual firms or models with risk neutral agents naturally emphasize the variance of the shocks facing the firm rather than any covariances with shocks to other firms. These models predict a positive or negative effect of uncertainty depending on whether the marginal revenue product of capital is a convex or concave function of the shock. In the case of convexity, a mean preserving spread in the distribution of the shock will increase the return to investment via Jensen's inequality.

In the models of Oi (1961), Hartman (1972, 1976), and Abel (1983), it is the flexibility of labor relative to capital that produces the convex returns. If labor and capital are fixed, then the marginal revenue product of capital is linear in output price. In contrast, if labor can adjust to price shocks, then price fluctuations lead the firm to change its labor-capital ratio, thus causing the marginal revenue product of capital to change by more than the movement in price. A similar argument shows that the marginal revenue product of capital is convex in wages as well. There are other ways to rationalize convex returns. Roberts and Weitzman (1981) show that if a firm has the option to abandon a project, then an increase in uncertainty increases the incentive to invest. Bar-Ilan and Strange (1992) find a similar effect in a model with costly entry and exit and time-to-build. In Stiglitz and Weiss (1981) uncertain projects are more desirable since bankruptcy limits downside risk.

The main class of models that predict a concave marginal revenue product of capital are those with irreversible investment. ${ }^{1}$ Irreversibilities make returns to investment asymmetric. If the future turns out to be worse than expected, the marginal revenue product of capital falls, and the investor is stuck with low returns. If, on the other hand, prospects improve, the incentive is to invest more, thereby limiting the rise in the marginal revenue product of capital. This asymmetry implies that the marginal revenue product of capital is a concave function of wages and prices. ${ }^{2}$ Hence, like the CAPM, greater uncertainty tends to make investment less desirable. Unlike the CAPM, however, uncertainty has a direct effect on investment-one that is independent of the correlation of investment with the 
market as a whole. All uncertainty increases downside risk without creating corresponding upside gains. ${ }^{3}$

In this paper we develop a measure of the uncertainty facing a firm from the variance of asset returns. We use this measure to study the relationship between investment and uncertainty in a panel of firms from COMPUSTAT. We then perform various sample splits in order to test comparative static implications of the theories outlined above and see to what extent they help explain this relationship. The main results are that uncertainty exerts a strong negative influence on investment and that this influence bears little relationship to risk as conventionally measured. These results argue in favor of theories in which uncertainty affects investment directly rather than working through covariances, and in favor of models in which the marginal revenue product of capital is concave. These simple facts appear to be at variance with the CAPM and the Oi-Hartman-Abel theory. This leaves irreversibilities as the most likely explanation of the relationship between investment and uncertainty.

We organize the paper by first reviewing the related empirical literature in Section 2. Section 3 covers our tests of the implications of the above theories on the sign of the investment-uncertainty relationship. Section 4 discusses our results, and Section 5 concludes.

\section{Related Literature}

Few empirical studies have been done on the relationship between investment and uncertainty, and what work exists is far from conclusive. For example, Brainard, Shoven, and Weiss (1981) use a sample of 187 firms from the years 1958 to 1977 to assess the affects of a CAPM-based measure of risk on investment via average $q$, the ratio of the market to the book value of the capital stock. Their results are mixed. Instead of using the panel aspect of their data set, they perform individual cross-section regressions of $q$ on their measure of risk, finding both positive and negative coefficients on risk, only some of which 
are significant.

Ferderer (1993) uses the term structure of interest rates to derive a measure of the risk premium on long term bonds. He finds that this measure of uncertainty has a significant negative effect on aggregate investment even after controlling for user cost and Tobin's q. His approach has the advantage that it uses a forward looking measure of uncertainty that matches the forward looking nature of investment. His use of aggregate data, however, suffers from several drawbacks. First, his measure of uncertainty is countercyclical and leads the business cycle. This means that there is some chance that investment is reacting to changes in the level of demand and not to changes in uncertainty about demand. Second, he examines interest rate uncertainty, which only captures one aspect of the uncertainty facing a firm. Third, his use of aggregate data may be a source of simultaneity problems. Aggregates must obey aggregate budget constraints. It is therefore difficult to isolate the direct effect of uncertainty on investment from the indirect effect through savings behavior. For example, the presence of precautionary saving could introduce a correlation between uncertainty and investment where none might otherwise exist.

Pindyck and Salimano (1993) and Caballero and Pindyck (1993) test an implication of models of irreversible investment. If investment is irreversible, firms invest only after the marginal revenue product of capital has crossed some threshold, and under standard assumptions this threshold is increasing in uncertainty. Both papers use the maximal observed value of the marginal revenue product of capital within a country or an industry as a proxy for the investment trigger, and the variance in the marginal revenue product of capital as a proxy for uncertainty. They then examine the cross sectional relationship between these two measures and find a "sizable but not overwhelming" effect of uncertainty on the investment trigger. They note, however, that these results are biased due to a natural correlation between the maximum and the variance of a sequence of random variables that would exist even if uncertainty did not effect investment.

Hurn and Wright (1994) test another implication of models of irreversible invest- 
ment. They look at the effect of the level and variance of oil prices on the delay between the discovery of an oil field in the North Sea and the decision to develop it. If irreversibilities matter, then uncertainty about the price of oil should increase this delay. Using a discrete-time hazard model, they find that although the price of oil matters for the delay, the variance of the price does not. However, they do not use a forward-looking measure of uncertainty, instead calculating the variance by assuming that oil prices follow a random walk. The authors themselves note that oil prices are better characterized by a jump process. ${ }^{5}$

In sum, although most economists would probably find plausible the loose intuitive idea that uncertainty reduces investment, the above discussions demonstrate that economic theory does not provide such a clear conclusion and that the empirical evidence on the issue is far too scanty to assert with confidence that we can sign the investment-uncertainty relationship. We therefore believe that there is room to explore the subject further.

\section{Empirical Implementation}

We use panel data on individual firms to test the relationship between uncertainty and investment. The use of firm-level data has several advantages. First, it allows us to concentrate on measures of uncertainty closely related to the firm's environment. Recent research by Davis and Haltiwanger (1992) argues strongly that most shocks are idiosyncratic to the firm or plant. Macroeconomic studies may therefore mismeasure uncertainty. Second, the use of panel data should reduce simultaneity problems. Since the effect that uncertainty has on saving influences investment only through the interest rate, time dummies should mitigate this effect. Time dummies will also eliminate a spurious correlation between investment and uncertainty arising from the relationship between uncertainty and the business cycle.

Our strategy is first to analyze the reduced form relationship between investment and uncertainty over our entire sample of firms, with the intent of signing this relationship 
and determining the relative importance of variances and covariances. We then perform various sample splits aimed at capturing important properties of particular theories discussed in the introduction.

We focus on reduced forms for several reasons. First, it is very difficult to construct a single structural model that embeds each of the theories of investment under uncertainty as special cases. Second, even if it were possible to construct such a model, it is not clear that estimating it directly would be the best strategy for determining the sign of the investment-uncertainty relationship. On one hand, this approach would provide a direct link between the underlying theory and this sign, which could be inferred from the model's parameters. On the other hand, as is always the case with structural estimation, the resulting inference would likely be fragile with respect to the choice of assumptions used to derive an estimable equation from the model. Finally, we are not interested in the "fit" of any particular model -only in the sign of the investment-uncertainty relationship, and this we can learn this from a reduced form. This sign alone tells us whether to favor models with convex or concave marginal revenue products of capital.

We now describe our empirical methodology in detail, beginning with the central issue of how we measure uncertainty. We then discuss our estimation procedure and introduce the data set.

\section{A. Measuring Uncertainty}

It is clear that uncertainty can take many forms. Firms may be uncertain about future prices and wages, or they may be uncertain about future productivity. The source of uncertainty may be changes in consumer's tastes, technology, or institutions. Even if we could pinpoint the most important sources of uncertainty, measuring uncertainty poses many difficulties. Reasonably high-quality output price data is not available on a sufficiently disaggregated basis, and technology shocks are largely unobservable. Moreover, uncertainty concerns not what actually happens but what might occur, and data on expectations are 
notoriously poor.

Given the difficulty inherent in identifying and measuring specific sources of uncertainty, we obtain a general measure of the uncertainty facing a firm from the variance of the firm's daily stock return for each year in the sample. ${ }^{6}$ The advantage of this strategy is that asset returns capture the effects of any aspect of a firm's environment that investors deem important. The disadvantage is that movements in asset returns may be quite noisy, reflecting not only changes in fundamentals, but also bubbles, fads, and the influence of noise traders. Note that we scale the variance by the firm's debt-equity ratio, since all else equal, the return variance will increase with the leverage of the firm.

Since uncertainty relates to expectations and not to actual outcomes, it would be incorrect to use the ex post volatility of asset returns as a measure of the variability of the firm's environment. We therefore need an ex ante measure. One solution to this problem is to extract a forecast of return variance from option prices. However, options on individual stocks are available only for a small subsample of the firms in our data set and even then have at most a six month maturity-a horizon we believe to be too short for most investment projects. Another solution is to use a GARCH model on the individual time series of each firm to estimate a forecast of volatility. Although this approach does away with the short horizon problem, we can obtain unbroken time series of over ten years for less than half of the firms in our sample. ${ }^{7}$ We propose an alternate solution by constructing forecasts of volatility using a vector autoregression technique, which also allows us to look at a longer than six month horizon.

It will also be necessary to obtain a measure of risk in order to evaluate the CAPM. To measure the risk of an individual firm we use the covariance of the firm's daily stock return with a value weighted index of the NYSE, AMEX, and NASDAQ. Although Craine (1988) points to a covariance of the marginal product of capital with consumption as the appropriate measure of risk, we prefer a market-based measure since data on aggregate consumption are likely to be of poor quality at high frequency (See Wilcox (1992)). 


\section{B. Specification}

As discussed above, since we are not interested per se in testing the models described in the introduction, but only in learning about the sign of the investment-uncertainty relationship, linear regressions of the rate of investment on various measures of uncertainty suffice for our purposes. If we could observe forward looking measures of uncertainty, such a regression would take the following form:

$$
\left(\frac{I}{K}\right)_{i t}=c_{t}+f_{i}+\sum_{n=0}^{N} \alpha_{n} E_{t} \sigma_{i, t+n}+u_{i t}
$$

Here, $c_{t}$ is a time-varying intercept, $f_{i}$ is an individual fixed effect, and $E_{t} \sigma_{i, t+n}$ is the beginning of time $t$ expectation of the $n$-period ahead forecast of a vector containing the variance of a firm's return and the covariance of this return with the market.

The firm specific effects, $f_{i}$, play an important role in role in the estimation. With a short time horizon and large cross section, most of our identification will come from the cross section. The cross-sectional relationship between the level of uncertainty and the level of investment, however, is likely to be noisy, since theory states that uncertainty affects investment through the required rate of return and many other firm specific factors will affect the level of investment consistent with a given rate of return. With the inclusion of the fixed effects, we will not be able to identify $\alpha_{n}$ unless $E_{t} \sigma_{i, t+n}$ varies with $t$. Most of the identification will come from comparing changes in uncertainty to changes in investment. This relationship should be much less noisy; the theories discussed in the introduction all imply that changes in uncertainty should feed more or less directly into changes in investment. $^{8}$

It is also worth noting that in most of the papers surveyed in the introduction the effect of uncertainty on investment operates through the marginal revenue product of capital, which in the context of a multi-period model becomes marginal $q .{ }^{9}$ Therefore, if we control for $q$ in (1), we ought to find that our measure of uncertainty becomes insignificant. We explore this possibility below. 
Two basic issues arise in the estimation of (1). First, to eliminate the unobservable fixed effects in (1), we difference the equation and rewrite it as:

$$
\Delta\left(\frac{I}{K}\right)_{i t}=\Delta c_{t}+\sum_{n=0}^{N} \alpha_{n} \Delta E_{t} \sigma_{i, t+n}+\Delta u_{i t}
$$

Second, we must measure the subjective expectations $E_{t} \sigma_{i, t+n}$, which are clearly unobservable. To this end, we assume that $\sigma_{\text {it }}$ follows a stationary stochastic process with a finite order autoregressive representation:

$$
\sigma_{i t}=d_{t}+g_{i}+\sum_{n=1}^{M} \gamma_{n} \sigma_{i, t-n}+\epsilon_{i t}
$$

where $d_{t}$ is a vector of time-varying intercepts, and $g_{i}$ is vector of individual unobserved effects. $\gamma_{n}$ are $2 \times 2$ coefficient matrices, and $\epsilon_{i t}$ is the innovation in $\sigma_{i t}$, which will be orthogonal to $\sigma_{i, t-j}$, for $j \geq 1$.

As before, we difference (3) to eliminate $g_{i}$.

$$
\Delta \sigma_{i t}=\Delta d_{t}+\sum_{n=1}^{M} \gamma_{n} \Delta \sigma_{i, t-n}+\Delta \epsilon_{i t}
$$

Note now that the transformed innovation will be orthogonal to $\sigma_{i, t-j}$, for $j \geq 2$. We can apply the law of iterated expectations to (4) to derive a beginning-of-period $t$ forecast of $\Delta \sigma_{i, t+n}$. Let $\Delta \sigma_{i, t+n}^{*}$ denote this forecast, and let $\Delta \nu_{i, t+n}$ denote the discrepancy between the observable $\Delta \sigma_{i, t+n}^{*}$ and the unobservable $\Delta E_{t-1} \sigma_{i, t+n}$. This error will by construction be orthogonal to $\sigma_{i, t-j}$ for $j \geq 2$. We can use these constructed forecasts to rewrite (2) as

$$
\Delta\left(\frac{I}{K}\right)_{i t}=\Delta c_{t}+\sum_{n=0}^{N} \alpha_{n} \Delta \sigma_{i, t+n}^{*}+\sum_{n=0}^{N} \Delta \nu_{i, t+n}+\Delta u_{i t}
$$

We estimate (3) and (5) using a two-step procedure described below. With the inclusion of firm-specific and time-specific fixed effects, most of the identification in our model will come from cross-sectional differences in investment and uncertainty across firms. Aggregate phenomenon such as recessions or changes in interest rates will only influence our results to the extent that their effects are nonlinear or differ across firms and therefore not captured by the time dummies. 


\section{Estimation}

To estimate (3), we use the procedure developed by Holtz-Eakin, Newey, and Rosen (1988), which adapts VAR estimation to panels with a short time dimension. The technique allows for a great deal of heterogeneity among cross-sectional units, both in terms of individual fixed effects and heteroskedasticity. Estimation proceeds by applying generalized method of moments to the cross product of $\Delta \epsilon_{i t}$ and a vector containing $\sigma_{i, t-j}$, for $j \geq 2$, which, as noted above, should be orthogonal to $\Delta \epsilon_{i t}$ in the population. Note that in the problem at hand, GMM is equivalent to instrumental variables with a robust variance-covariance matrix. To determine the maximum appropriate lag length in (3), we start with a trial value of three and then decrease this value until the sum of squared errors of the model is too "large," where the metric we use is a GMM equivalent to a standard likelihood ratio test developed by Newey and West (1987). We use similar procedures to estimate (5), where we calculate two-step GMM standard errors using the procedure in Newey (1984).

\section{Sample Splits}

One implication of CAPM based theories is that firms whose returns are highly correlated with the market should be more sensitive to uncertainty about their own returns. To see this point, note that the covariance between an investment's return and the market return is the product of two terms: the variance of the return on the investment and the investment's $\beta$. Therefore, the sensitivity of a firm's investment to changes in uncertainty should depend on that firm's $\beta$; the greater $\beta$, the more undesirable uncertainty. To test this implication, we split the sample at the median into high and low $\beta$ subsamples.

We also examine two implications of the convex returns theories. First, the ability to substitute labor for capital should lessen the negative effect of uncertainty on investment by increasing convexity of the marginal product of capital. To test this implication, we split the sample at the median on the basis of industry variances of the labor-capital ratio, the idea being that greater variability in this ratio indicates a greater ability to substitute labor 
for capital. ${ }^{10}$ The second implication, found in Abel (1983), is that higher labor-capital ratios should reduce the undesirability of uncertainty. The intuition for this result is that the higher is labor's share, the greater is the convexity in returns induced by varying the firm's labor input. In this case we split the sample by the industry labor-capital ratios. ${ }^{11}$

\section{E. Data}

Our data are from the manufacturing firms (SIC codes 2000-3999) in the combined annual and full coverage 1991 COMPUSTAT industrial files. We delete firms with missing or inconsistent data or involved in a merger that accounts for greater than fifteen percent of book value assets. The sample thus obtained runs from 1981 to 1987 and contains 772 firms. ${ }^{12}$ The data on stock returns are from the 1990 CRSP tapes and are adjusted to account for stock splits and dividend disbursements. We obtained this data for 600 of the firms in the original COMPUSTAT sample. Here, we delete any firm that has over half of its observations missing in any of the six years. We present a detailed description of the variables in the data appendix.

Finally, since few firms in COMPUSTAT report data on the administrative and production components of variable costs, we turn to a third data source in order to test hypotheses concerning the labor to capital ratio and the degree of substitutability between labor and capital. We use annual two-digit industry level data on real capital, labor, energy, and materials from the U.S. Bureau of Labor Statistics. These data run from 1949 to 1987. Here, in using aggregate data, we face a tradeoff between encountering aggregation bias and not being able to look at the above comparative static results at all. For example, not all firms in a two-digit industry may have labor-capital ratios that lie above the cut-off point for our sample split, even though the average industry ratio does. Nonetheless, since this bias should affect the magnitude but not sign of the coefficient, we believe that these data can provide us with a rough picture of the effects of labor-capital ratios and substitutability on our results. 
Table 1 reports summary statistics for our whole sample and for the various sample splits described in the previous section. Note here that since the return variance and the covariance between the individual return and the market return are measured in percent squared, we have multiplied each of these numbers by 10,000 to put them in the same units as the rate of investment and $q$.

\section{Results}

We report our findings for the effects of $E_{t} \sigma_{i t}{ }^{13}$ Table 2 contains the results from the instrumental variable regressions of the rate of investment on measures of uncertainty and risk for the full sample. For reference, we first regress the rate of investment, $(I / K)_{i t}$, on Tobin's q. As expected, the coefficient is small, positive, and highly significant. A $10 \%$ rise in $q$ from its mean leads to a $4 \%$ increase in the rate of investment from its mean. We then regress $(I / K)_{i t}$ on the variance, finding a coefficient that is negative and significant with a p-value of .051 . A $10 \%$ increase in the variance leads to a $1.7 \%$ fall in the rate of investment. Note that in Table 1 the mean and standard deviation of the variance are nearly identical, implying that $10 \%$ differences in the variance of returns are quite common in the data.

As noted in the previous section, many theoretical models predict that the effect of uncertainty on investment operates through marginal $q$. The third column of Table 2 shows that the coefficient on the variance becomes insignificant when we control for the effects of the standard proxy for marginal $q$-Tobin's $q$. We interpret this as evidence that uncertainty affects investment mainly through marginal $q \cdot{ }^{14}$ Loosely speaking, although firms' investment responds primarily to the first moment of the rate of return, the second moment influences the first.

The next two columns present analogous results for the CAPM-based measure of uncertainty, the covariance. Here, the results are not as strong. In neither column is the coefficient on the covariance significant. It appears that changes in the covariance have 
very little effect on investment. In the next column we regress the rate of investment on both variance and covariance. The coefficient on the variance is negative and significant, while the coefficient on the covariance is positive but insignificant. Finally, when we control for $q$, we once again find that both of these coefficients become insignificant.

One possible explanation for these results may be that the variance is highly correlated with other variables that traditionally explain investment. Chirinko (1993) notes that many papers in the literature have found both output and cash flow to be significant in investment regressions, where output controls for heterogeneity in market structure and cash flow controls for differences in access to capital markets. ${ }^{15}$ To examine this possibility we present in Table 3 the results of adding these two variables (normalized by the capital stock) to our regressions. Note first in columns one through four that this modification changes the basic pattern of results little. Both variance and covariance remain insignificant when we control for $q$, output, and cash flow. In the last four columns we omit $q$ from the regressions, and find that the coefficient on variance remains negative and significant.

These additional results add credence to the hypothesis that uncertainty affects investment only through $q$. We investigate the relationship between $q$ and uncertainty further by regressing $q$ on the variance and the covariance. Here, using twice-lagged $\sigma_{i t}$ as instrumental variables solves a further simultaneity problem. For example, suppose that a negative productivity shock makes $q$ fall and also causes an increase in uncertainty. Then this productivity shock will be in the error term of the regression of $q$ on uncertainty and will be negatively correlated with uncertainty. Therefore, an OLS estimate of the coefficient on our variance forecast will be biased downwards. However, twice-lagged $\sigma_{i t}$ should be uncorrelated with any serially uncorrelated productivity shock. ${ }^{16}$ Therefore, our instrumental variables procedure should lessen this bias. The results are presented in Table 4. We see in the first column that the predictable component of the variance of returns has a highly significant effect on $q$. In fact a $10 \%$ increase in the variance leads to a $5 \%$ decrease in $q$. In the second column, we see that this correlation survives even if we 
control for the stock price. Since variation in equity values is the largest contributor to the variation in $q$, omitting the stock price from the regression may result in serious omitted variables bias. The covariance, on the other hand, bears a much weaker relationship with $q$, as can be seen from the third and fourth columns. Finally, if both the variance and covariance are included in the regression, as in the final two columns of Table 4, we see that the negative correlation between the variance and $q$ becomes stronger, while the sign on the covariance is positive and insignificant.

The results for the full sample do not augur well for risk-based explanations of the relationship between investment and uncertainty. If the covariance captured risk, it should have performed at least as well as the variance. We give the CAPM based theories another chance by testing one further implication: that firms whose returns are highly correlated with the market should be more sensitive to changes in the variance. To test this implication, we split the sample at the median into high and low $\beta$ subsamples and then repeat the seven regressions discussed above on each of these subsamples. The results are reported in Table 5. The most interesting column is the second one in which we regress the rate of investment on our forecast of uncertainty. If the CAPM is correct, the coefficient should be greater for the high $\beta$ sample. The point estimates go in the opposite direction, although the regression coefficient for the low $\beta$ sample is imprecisely measured and the coefficients in the two samples are not significantly different. We therefore find no evidence that uncertainty affects investment in the manner indicated by the CAPM.

The negative coefficient on the variance in the full-sample regression casts doubt on the importance of theories that emphasize the convexity of the marginal revenue product of capital. If these theories were correct, we would have expected to see a positive coefficient on the variance. It may be, however, that these theories have some merit, but that their influence is drowned out by the power of some other effect such as irreversibility. To test this hypothesis we examine two implications of the Oi-Hartman-Abel substitutability theory: the ability to substitute labor for capital should lessen the negative effect of uncertainty on 
investment, as should higher labor-capital ratios. ${ }^{17}$ To test the first implication, we split the sample at the median on the basis of industry variances of the labor-capital ratio. The results are presented in first two sections of Table 6. Again the most interesting regression appears in the second column, where we see that contrary to the theory, uncertainty is more harmful the more variable is the labor-capital ratio. ${ }^{18}$ To test the second implication, we split the sample on the basis of the level of the industry labor-capital ratios. The second column of the second section of Table 6 shows again that the effect of uncertainty, contrary to theory, is more negative in the high labor-capital ratio sample. We therefore find no evidence in support of the Oi-Hartman-Abel theory.

\section{Conclusion}

Recent theoretical work has presented conflicting predictions of the response of investment to uncertainty. The purpose of this study has been to ascertain the direction of this relationship for a panel of U.S. corporations. Our results indicate that an increase in uncertainty decreases investment, primarily through its effect on $q$. In addition, we find no evidence for a positive effect via the channel of the convexity of the marginal product of capital or for the presence of a CAPM-based effect of risk. This leaves irreversible investment as the most likely explanation for the observed correlation between investment and uncertainty. 


\section{Data Appendix}

This appendix is organized as follows. First we describe in general terms the variables used in the regressions. We then set out the details of the calculations of the underlying variables used to construct the regression variables. In what follows we have we have dropped the $i$ subscript for convenience.

Investment : $I_{t}$ is reported spending on plant, property, and equipment. It does not include spending on acquisitions.

Tobin's $q$ : we calculate $Q_{t}$ as follows:

$$
Q_{t}=\frac{D_{t}+E_{t}-I N V_{t}}{K_{t-1}}
$$

$D_{t}+E_{t}-I N V_{t}$ represents the market value of the capital stock. Here, we have subtracted the replacement value of inventories from the sum of the market values of debt and equity, since inventories are included in the market value of the firm but do not contribute to the market value of the capital stock itself.

Output : we calculate output as sales minus the change in finished goods inventories.

Cash Flow : we calculate output as the sum of operating income and depreciation charges.

Replacement Value of Inventories : For firms using the FIFO method, inventories are valued at current cost; and book value equals replacement value. However, for firms using LIFO, inventories are valued at historical cost. To convert book to replacement value, we first assume that the reported value of LIFO inventories is equal to the replacement value for the first year the firm appears on the tape. Following Salinger and Summers (1983), we assume that inventories are rolled over each year and use the following formulas to calculate their replacement value:

$$
I N V_{t}=I N V_{t-1}\left(P P I_{t} / P P I_{t-1}\right)+I N V_{t}^{*}-I N V_{t-1}^{*} \text { if } I N V_{t}^{*} \geq I N V_{t-1}^{*}
$$




$$
I N V_{t}=\left(I N V_{t-1}+I N V_{t}^{*}-I N V_{t-1}^{*}\right)\left(P P I_{t} / P P I_{t-1}\right) \text { if } I N V_{t}^{*}<I N V_{t-1}^{*}
$$

Here, $I N V_{t}$ is the replacement value of LIFO inventories at time $t$ and $I N V_{t}^{*}$ is their reported value.

Replacement Value of the Capital Stock : In order to convert the book value of the gross capital stock into its replacement value, we use the perpetual inventory method described in Salinger and Summers (1983). First, we set the replacement value of the capital stock equal to the book value of gross plant, property, and equipment for the first year the firm appears on the tape. For $43 \%$ of the firms, this starting date occurs before 1962, when low inflation would not have caused much of a gap between the replacement value of capital and figures based on historical cost. For new firms that appear on the tape in later years, the book value of the capital stock in the first year is a reasonable approximation for the replacement value. However, for existing firms that appear in later years, this approximation will not be as good. Using the net value of plant, property, and equipment did not alter the empirical results significantly.

Next, we estimate the useful life of capital goods in any year using the formula:

$$
L_{t}=\frac{G K_{t-1}+I_{t}}{D E P R_{t}}
$$

Here $L_{t}$ is the useful life of capital goods at time $t$ and $G K_{t-1}$ is the reported value of gross property, plant, and equipment at time $t-1$. We then take the average over time of $L_{t}$ and use this average value, $L$, in the following formula to define the replacement value of the capital stock:

$$
K_{t}=\left(K_{t-1}\left(\frac{P_{t}^{k}}{P_{t-1}^{k}}\right)+I_{t}\right)(1-2 / L)
$$

The second term represents the amount of the capital stock that depreciates each year and is based on the assumption that economic depreciation is double declining balance. See Salinger and Summers (1983) for the other assumptions necessary to use this method of calculation. 
Market Value of Equity : $E_{i t}$ is calculated as the sum of the market value of preferred stock and the market value of common stock. The latter is calculated simply as the number of common shares outstanding times the end-of-year share price. The market value of preferred stock is its dividend capitalized by Moody's medium-grade dividend yield, under the assumption that dividends are paid forever.

Market Value of Debt : we use the method set forth in Bernanke and Campbell (1988) to convert the book value of debt into the market value. Since COMPUSTAT only provides limited information on the different maturities of debt, it is necessary to construct the maturity distribution of long term debt from historical information on debt issues. The first step consists of using the method of Brainard, Shoven, and Weiss (1980) to construct the maturity distribution of book debt under the assumption that all longterm debt matures in twenty years. First, each individual firm's maturity distribution is set equal to the aggregate for the first year that the firm appears on the tape. Then, if $D_{j t}$ is debt due in $j$ years at time $t, L T D_{t}$ is the reported value of long term debt at time $t$, and $D r_{t}$ is the amount of debt issued at time $t$, the maturity distribution is updated as follows:

$$
\begin{array}{r}
D_{20 t}=D I_{t}=L T D_{t}-\left(L T D_{t-1}-D_{1, t-1}\right) \text { if } L T D_{t}-\left(L T D_{t-1}-D_{1, t-1}\right) \geq 0 \\
D_{20 t}=D I_{t}=0 \text { if } L T D_{t}-\left(L T D_{t-1}-D_{1, t-1}\right)<0
\end{array}
$$

and

$$
D_{j t}=D_{j+1, t-1}, j=1, \ldots, 19
$$

If $L T D_{t}-\left(L T D_{t-1}-D_{1, t-1}\right)<0$, debt retirement is distributed proportionately across the maturity distribution; that is, debt due in one to nineteen years is scaled down by the factor: 


$$
\frac{L T D_{t}}{L T D_{t-1}-D_{1, t-1}}
$$

The second step consists of replacing the estimated values of debt due in years one through five with the actual COMPUSTAT numbers and rescaling the rest of the maturity distribution to be consistent with the total amount of long term debt.

$$
\begin{gathered}
D_{j t}^{a}=D_{j t}^{*}, j=1, \ldots, 5 \\
D_{j t}^{a}=D_{j t}\left(1+\left(\sum_{j=1}^{5}\left(D_{j t}-D_{j t}^{*}\right)\right) \div\left(\sum_{j=6}^{20} D_{j t}\right)\right), j=6, \ldots, 20
\end{gathered}
$$

Here, $D_{j t}^{a}$ is the adjusted value of debt due in $j$ years and $D_{j t}^{*}$ is the reported value of debt due in $j$ years for $j$ equal to one through five.

The final modification adjusts the value of total book debt to make reported interest expense consistent with that implied by assuming that the firm's interest rate on debt issued at time $t$ is the Baa rate at time $t$. First, the new value of total book value is scaled as follows:

$$
N L T D_{t}=L T D_{t} \times I E X_{t} \div\left(\sum_{j=1}^{20} \mathrm{Baa}_{t+j-20} D_{j t}^{a}\right),
$$

where $N L T D_{t}$ is the scaled value of long term debt at time $t, \mathrm{Baa}_{t}$ is the interest rate on grade Baa bonds at time $t$, and $I E X_{t}$ is the reported amount of interest expense at time $t$. The new maturity distribution is then set proportional to the old.

Covariance : This variable is calculated as the daily covariance of the individual return on the market return, where the latter is calculated as the value-weighted returns on the NYSE, AMEX, NASDAQ.

Variance : Our variance variable is the variance of the daily return. Both the covariance and variance are calculated for each year and are adjusted by the market debt to equity ratio. 


\section{Endnotes}

1. The single-firm irreversible investment problem is analyzed by Bernanke (1983), Pindyck (1988), Bertola (1987), and Dixit (1989). Leahy (1993) shows that the single firm intuition extends to risk neutral firms in a competitive industry.

2. In order for irreversibilities to matter, some link must exist between current and future investment. This may arise from decreasing returns to scale, downward sloping demand, or a limit on firm investment. In models with linearly homogeneous technology and perfectly elastic demand, such as Abel (1982), irreversibilities play no role.

3. Irreversible investment models do not always predict a negative correlation between uncertainty and investment. Ingersoll and Ross (1992) note that the effect of interest rate uncertainty is ambiguous because present values are convex functions of interest rates. See also Bar-Ilan and Strange (1992).

4. This last point is a bit puzzling since most theories of investment under uncertainty imply that uncertainty affects investment only through $q$.

5. Two more papers deserve note. Bizer and Sichel (1990) find evidence that firms incur greater adjustment costs from disinvesting than from investing. As evidence for irreversibilities, this study provides indirect evidence on the sign of the investmentuncertainty relationship. Rust (1987) estimates a structural model of bus-engine replacement, but does not analyze the effect of uncertainty on investment.

6. We have also tried using weekly and monthly returns, with little change in the qualitative results.

7. Using a GARCH forecast as our measure of uncertainty yields qualitatively similar results, except that the smaller sample raises our standard errors and prevents us from making sharp inferences. 
8. Most models of irreversible investment consider only the case in which $\sigma$ is constant. Hassler (1993) constructs a model in which $\sigma$ follows a two state Markov process and shows that increases in uncertainty reduce investment. Interestingly, the effect of the change is stronger the more transient is the change in uncertainty.

9. Abel and Eberly (1993) construct a model that nests the model of Abel (1983) and an irreversible investment model. They show that under general assumptions investment depends only on marginal $q$ and the capital stock, so that uncertainty affects investment only through marginal $q$.

10. We also substitute total variable factors for labor with little difference in the results.

11. The comparative static implications of irreversible investment models for observables are less clear cut. See Pindyck and Salimano (1993). We therefore do not perform any sample splits to test for irreversibilities.

12. We stop our sample in 1987 because of an accounting change in 1988 that consolidated the balance sheets of wholly owned subsidiaries. See Bernanke, et. al. (1990).

13. Using a two-year forecast $\left(E_{t} \sigma_{i, t+1}\right.$, given our timing notation) gives qualitatively similar results. For longer-horizon forecasts, the two-step regression standard errors become too large to make any inferences. It should also be noted that using actual volatility measures changes neither the sign nor the significance of the coefficients on the variance and covariance.

14. Ferderer (1993) finds that his measure of uncertainty affects investment independently of $q$.

15. Hayashi (1982) shows that if a firm has monopoly power than the difference between marginal and average $q$ is related to a weighted average of current and future output. 
16. Note that the time dummies will subsume any macroeconomic component of the shock, and that differencing removes any time-invariant, firm-specific component.

17. These comparative statics are implicit in Abel (1983).

18. One possible explanation for this result is that firms will choose technologies with variable labor to capital ratios if they find uncertainty particularly costly. 


\section{Literature Cited}

Abel, Andrew B. "Optimal Investment under Uncertainty." American Economic Review 73 (1983), 228-233.

Abel, Andrew B, and Janice C. Eberly. "A Unified Model of Investment under Uncertainty." American Economic Review, forthcoming.

Bar-Ilan, Avner, and William Strange. "Investment Lags." Mimeograph, University of British Columbia, 1992.

Bernanke, Ben S. "Irreversibility, Uncertainty, and Cyclical Investment." Quarterly Journal of Economics 98 (1983), 85-106.

Bernanke, Ben S. and John Y. Campbell. "Is there a Corporate Debt Crisis?" Brookings Papers on Economic Activity 1 (1988), 83-125.

Bernanke, Ben S., John Y. Campbell, and Toni M. Whited. "U.S. Corporate Leverage: Developments in 1987 and 1988." Brookings Papers on Economic Activity 1 (1990), $255-278$.

Bertola, Giuseppe, "Irreversible Investment." Mimeograph, M.I.T., 1987.

Bizer, David, and Daniel Sichel. "Asymmetric Adjustment Costs, Capital Longevity, and Investment." Mimeograph, Federal Reserve Board, 1990.

Brainard, William, John Shoven, and Laurence Weiss. "The Financial Valuation of the Return to Capital." Brookings Papers on Economic Activity 2 (1980), 453-502.

Caballero, Ricardo J. and Robert Pindyck. "Uncertainty, Investment, and Industry Evolution." Mimeograph, M.I.T., 1993. 
Chirinko, Robert S. "Business Fixed Investment Spending: Modeling Strategies, Empirical Results, and Policy Implications." Journal of Economic Literature 31 (1993), 1875-1911.

Craine, Roger. "Risky Business: The Allocation of Capital." Journal of Monetary Economics 23 (1988), 201-218.

Davis, Steven J., and John Haltiwanger. "Gross Job Creation, Gross Job Destruction, and Employment Reallocation." Quarterly Journal of Economics 107 (1992), 819-864.

Dixit, Avinash. "Entry and Exit Decisions under Uncertainty." Journal of Political Economy 97 (1989), 620-638.

Ferderer, J. Peter. "The Impact of Uncertainty on Aggregate Investment Spending: An Empirical Analysis." Journal of Money, Credit, and Banking 25 (1993), 30-48.

Hartman, Richard. "The Effects of Price and Cost Uncertainty on Investment." Journal of Economic Theory 5 (1972), 258-66.

Hartman, Richard. "Factor Demand with Output Price Uncertainty." American Economic Review 66 (1976), 675-682.

Hassler, John. "Variations in Risk as a Cause of Fluctuations in Demand." Mimeo., M.I.T., 1993.

Hayashi, Fumio. "Tobin's Marginal $q$ and Average $q$ : A Neoclassical Interpretation." Econometrica 50 (1982), 213-224.

Holtz-Eakin, Douglas, Whitney Newey, and Harvey Rosen. "Estimating Vector Autoregressions with Panel Data." Econometrica 56 (1988), 1371-1395.

Hurn, A. S. and Robert E. Wright. "Geology or Economics? Testing Models of Irreversible Investment using North Sea Oil Data." Economic Journal 104 (1994), 363-371. 
Ingersoll, Jonathan, and Ross, Stephen A. "Waiting to Invest: Investment and Uncertainty." Journal of Business 65 (1992), 1-29.

Leahy, John V. "Investment in Competitive Equilibrium: The Optimality of Myopic Behavior." Quarterly Journal of Economics 108 (1993), 1105-1133.

Newey, Whitney. "A Method of Moments Interpretation of Sequential Estimators." Economics Letters 14 (1984), 201-206.

Newey, Whitney and Kenneth West. "Hypothesis Testing with Efficient Method of Moments Estimation." International Economic Review 28 (1987), 777-787.

Oi, Walter Y. “The Desirability of Price Instability." Econometrica 29 (1961), 58-64.

Pindyck, Robert S. "Irreversible Investment, Capacity Choice, and the Value of the Firm." American Economic Review 78 (1988), 969-985.

Pindyck, Robert S. and Andres Salimano. "Economic Instability and Aggregate Investment." National Bureau of Economic Research Macroeconomics Annual 1993.

Roberts, Kevin and Martin L. Weissman. "Funding Criteria for Research, Development, and Exploration Projects." Econometrica 49 (1981), 1261-1288.

Rust, John. "Optimal Replacement of GMC Bus Engines: An Empirical Model of Harold Zurcher." Econometrica 55 (1987), 999-1033.

Salinger, M. A. and Lawrence H. Summers. "Tax Reform and Corporate Investment: A Microeconomic Simulation Study." In Behavioral Simulation Methods in Tax Policy Analysis, edited by Martin Feldstein, Chicago, Illinois: University of Chicago Press, 1983.

Stiglitz, Joseph E. and Andrew Weiss. "Credit Rationing in Markets with Imperfect Information." American Economic Review 71 (1981), 393-410. 
Wilcox, David. W. "The Construction of U.S. Consumption Data: Some Facts and their Implications for Empirical Work." American Economic Review 82 (1992), 922-941. 
Table 1: Summary Statistics

The sample consists of 600 U.S. manufacturing firms from the COMPUSTAT data base from 1982 to 1987. Tobin's $q$ is measured at the beginning of the period. Variance is the debt-adjusted variance of the firm's stock return, and covariance is the debt-adjusted covariance of the return with the market return. These two variables have been rescaled to have the same units as the dependent variables. Price is the firm's beginning-of-period stock price. The dividing line for the high and low beta samplea is the median of the sample stock return beta. The high and low ex-post substitutability eamples are split evenly on the basis of industry variances of the capital labor ratio, and the high and low capital labor ratio samples are split evenly on the industry levels of this variable.

\begin{tabular}{|c|c|c|c|c|c|}
\hline & Investment/Capital & Tobin's $q$ & Variance & Covariance & $\overline{\text { Price }}$ \\
\hline \multicolumn{6}{|l|}{ Full Sample } \\
\hline Mean & 0.149 & 2.49 & 0.605 & 0.585 & 24.2 \\
\hline Median & 0.103 & 1.23 & 0.388 & 0.298 & 18.4 \\
\hline Standard Deviation & 0.225 & 4.58 & 0.706 & 0.978 & 23.0 \\
\hline \multicolumn{6}{|l|}{ High Beta Sample } \\
\hline Mean & 0.179 & 3.23 & 0.686 & 0.839 & 30.1 \\
\hline Median & 0.122 & 1.67 & 0.460 & 0.482 & 24.3 \\
\hline Standard Deviation & 0.268 & 5.49 & 0.748 & 1.21 & 27.3 \\
\hline \multicolumn{6}{|l|}{ Low Beta Sample } \\
\hline Mean & 0.117 & 1.70 & 0.519 & 0.314 & 17.9 \\
\hline Median & 0.0844 & 0.913 & 0.308 & 0.153 & 14.3 \\
\hline Standard Deviation & 0.160 & $3: 17$ & 0.648 & 0.521 & 14.8 \\
\hline \multicolumn{6}{|l|}{ High Ex-Post Substitutability Sample } \\
\hline Mean & 0.158 & 2.51 & 0.647 & 0.622 & 22.8 \\
\hline Median & 0.112 & 1.30 & 0.410 & 0.291 & 16.6 \\
\hline Standard Deviation & 0.260 & 4.06 & 0.785 & 1.09 & 23.9 \\
\hline \multicolumn{6}{|l|}{ Low Ex-Post Substitutability Sample } \\
\hline Mean & 0.137 & 2.46 & 0.552 & 0.538 & 25.8 \\
\hline Median & 0.0927 & 1.12 & 0.360 & 0.305 & 20.8 \\
\hline Standard Deviation & 0.170 & 5.16 & 0.588 & 0.812 & 21.6 \\
\hline \multicolumn{6}{|l|}{ High Labor to Capital Ratio Sample } \\
\hline Mean & 0.171 & 2.70 & 0.677 & 0.650 & 22.1 \\
\hline Median & 0.117 & 1.41 & 0.443 & 0.344 & 15.9 \\
\hline Standard Deviation & 0.262 & 4.27 & 0.770 & 1.05 & 23.6 \\
\hline \multicolumn{6}{|l|}{ Low Labor to Capital Ratio Sample } \\
\hline Mean & 0.106 & 2.08 & 0.465 & 0.459 & 28.1 \\
\hline Median & 0.0844 & 0.890 & 0.305 & 0.247 & 25.0 \\
\hline Standard Deviation & 0.110 & 5.11 & 0.536 & 0.814 & 21.0 \\
\hline
\end{tabular}

Table 2: The Effect of One-Period Uncertainty Forecasts on Investment: Full Sample

The sample consists of 600 U.S. manufacturing firms from the COMPUSTAT data base from 1982 to 1987. The dependent variable is Investment/Capital Stock. Standard errors, calculated using the procedure in Newey (1984), are in parentheses.

\begin{tabular}{lccccccc}
\hline \hline Tobin's $q$ & 0.024 & - & 0.022 & - & 0.025 & - & -0.061 \\
& $(0.009)$ & & $(0.023)$ & & $(0.010)$ & & $(0.208)$ \\
Variance & - & -0.538 & -0.054 & - & - & -0.768 & -2.51 \\
& & $(0.276)$ & $(0.536)$ & & & $(0.388)$ & $(5.80)$ \\
Covariance & - & - & - & -0.057 & 0.153 & 0.153 & 0.413 \\
& & & & $(0.087)$ & $(0.155)$ & $(0.155)$ & $(0.867)$ \\
\hline
\end{tabular}


Table 3: Effects of Controlling for Output and Cash Flow: Full Sample

The sample consists of 600 U.S. manulacturing firms from the COMPUSTAT data base from 1982 to 1987 . The dependent variable is Investment/Capital Stock. Cash flow and output are normalized by the capital stock. Standard errors, calculated using the procedure in Newey (1984), are in parentheses.

\begin{tabular}{lccccccccc}
\hline \hline Tobin's $q$ & 0.038 & 0.032 & 0.040 & 0.031 & - & - & - & - \\
& $(0.017)$ & $(0.038)$ & $(0.019)$ & $(0.020)$ & & & & \\
Output & -0.071 & -0.066 & -0.075 & -0.072 & 0.046 & -0.039 & -0.018 & -0.053 \\
& $(0.070)$ & $(0.072)$ & $(0.075)$ & $(0.147)$ & $(0.021)$ & $(0.069)$ & $(0.049)$ & $(0.078)$ \\
Cash Flow & 0.401 & 0.401 & 0.402 & 0.376 & 0.305 & 0.392 & 0.323 & 0.408 \\
& $(0.308)$ & $(0.327)$ & $(0.335)$ & $(0.685)$ & $(0.286)$ & $(0.390)$ & $(0.333)$ & $(0.441)$ \\
Variance & - & -0.116 & - & -2.703 & - & -0.683 & - & -1.027 \\
& & $(0.710)$ & & $(3.503)$ & & $(0.361)$ & & $(0.502)$ \\
Covariance & - & - & 0.045 & 0.450 & - & - & -0.133 & 0.211 \\
& & & $(0.119)$ & $(0.586)$ & & & $(0.113)$ & $(0.198)$ \\
\hline
\end{tabular}

Table 4: The Effect of One-Period Uncertainty Forecasts on Tobin's $Q$ : Full Sample

The anmple consists of 600 U.S. manufacturing firme from the COMPUSTAT data base from 1982 to 1987. The dependent variable is Tobin's q. Standard errors, calculated using the procedure in Newey (1984), are in parentheses.

\begin{tabular}{lcccccc}
\hline \hline Variance & -22.2 & -18.8 & - & - & -28.7 & -36.6 \\
& $(9.16)$ & $(9.24)$ & & & $(11.4)$ & $(31.7)$ \\
Covariance & - & - & -3.55 & -4.50 & 4.28 & 6.81 \\
& & & $(2.16)$ & $(2.92)$ & $(3.83)$ & $(10.7)$ \\
Price & & 0.273 & - & 0.872 & - & -0.328 \\
& & $(0.333)$ & & $(0.177)$ & & $(1.06)$ \\
\hline
\end{tabular}

Table 5: The Effect of One-Period Uncertainty Forecasts on Investment: High and Low Beta Firms

The sample consists of 600 U.S. manufacturing firms from the COMPUSTAT data base from 1982 to 1987 . The dependent variable is Investment/Capital Stock. Standard errors, calculated using the procedure in Newey (1984), are in parentheses.

\begin{tabular}{ccccccccc}
\hline \hline High Beta Sample & & & & & & & \\
Tobin's $q$ & 0.028 & - & 0.028 & - & 0.028 & - & 0.032 \\
& $(0.011)$ & & $(0.018)$ & & $(0.011)$ & & $(0.038)$ \\
Variance & - & -0.371 & -0.0024 & - & - & -0.581 & 0.091 \\
& & & $(0.199)$ & $(0.284)$ & & & $(0.303)$ & $(0.817)$ \\
Covariance & - & - & - & -0.064 & -0.004 & 0.126 & -0.025 \\
Low Beta Sample & & & & & $(0.066)$ & $(0.061)$ & $(0.122)$ & $(0.173)$ \\
Tobin's $q$ & 0.021 & - & 0.019 & - & 0.020 & - & 0.019 \\
& $(0.015)$ & & $(0.016)$ & & $(0.015)$ & & $(0.015)$ \\
Variance & - & -0.406 & -0.229 & - & - & -0.402 & -0.212 \\
& & & $(0.409)$ & $(0.389)$ & & & $(0.452)$ & $(0.408)$ \\
Covariance & - & - & - & -0.129 & -0.086 & -0.005 & -0.024 \\
& & & & & $(0.206)$ & $(0.182)$ & $(0.336)$ & $(0.228)$ \\
\hline
\end{tabular}


Table 6: The Effect of One-Period Uncertainty Forecasts on Investment: Sample Splits Based on Factor Substitutability

The sample consiats of 600 U.S. manufacturing firms from the COMPUSTAT data base from 1982 to 1987. The dependent variable is Investment/Capital Stock. Standard errorn, calculated using the procedure in Newey (1984), are in parentheses.

\begin{tabular}{|c|c|c|c|c|c|c|c|}
\hline \multicolumn{8}{|c|}{ High Ex-Post Substitutability Sample } \\
\hline Tobin's $q$ & $\begin{array}{c}0.027 \\
(0.010)\end{array}$ & - & $\begin{array}{c}0.005 \\
(0.030)\end{array}$ & - & $\begin{array}{c}0.025 \\
(0.011)\end{array}$ & - & $\begin{array}{c}-0.021 \\
(0.070)\end{array}$ \\
\hline Variance & - & $\begin{array}{c}-0.628 \\
(0.282)\end{array}$ & $\begin{array}{c}-0.531 \\
(0.549)\end{array}$ & - & - & $\begin{array}{c}-0.726 \\
(0.399)\end{array}$ & $\begin{array}{c}1.26 \\
(1.66)\end{array}$ \\
\hline Covariance & - & - & - & $\begin{array}{c}-0.117 \\
(0.092)\end{array}$ & $\begin{array}{c}-0.041 \\
(0.077)\end{array}$ & $\begin{array}{c}0.069 \\
(0.158)\end{array}$ & $\begin{array}{c}0.143 \\
(0.287)\end{array}$ \\
\hline \multicolumn{8}{|c|}{ Low Ex-Post Substitutability Sample } \\
\hline Tobin's $q$ & $\begin{array}{c}0.015 \\
(0.017)\end{array}$ & - & $\begin{array}{c}0.018 \\
(0.026)\end{array}$ & - & $\begin{array}{c}0.017 \\
(0.020)\end{array}$ & - & $\begin{array}{c}0.014 \\
(0.028)\end{array}$ \\
\hline Variance & - & $\begin{array}{c}-0.175 \\
(0.410)\end{array}$ & $\begin{array}{c}0.081 \\
(0.561)\end{array}$ & - & - & $\begin{array}{c}-0.574 \\
(0.859)\end{array}$ & $\begin{array}{c}-0.202 \\
(0.883)\end{array}$ \\
\hline Covariance & - & - & - & $\begin{array}{c}-0.004 \\
(0.122)\end{array}$ & $\begin{array}{c}0.044 \\
(0.137)\end{array}$ & $\begin{array}{c}0.172 \\
(0.281)\end{array}$ & $\begin{array}{c}0.096 \\
(0.214)\end{array}$ \\
\hline \multicolumn{8}{|c|}{ High Labor to Capital Ratio Sample } \\
\hline Tobin's $q$ & $\begin{array}{c}0.025 \\
(0.010)\end{array}$ & - & $\begin{array}{c}0.020 \\
(0.014)\end{array}$ & - & $\begin{array}{c}0.025 \\
(0.010)\end{array}$ & - & $\begin{array}{c}0.020 \\
(0.017)\end{array}$ \\
\hline Variance & - & $\begin{array}{c}-0.641 \\
(0.330)\end{array}$ & $\begin{array}{c}-0.156 \\
(0.343)\end{array}$ & - & - & $\begin{array}{c}-0.702 \\
(0.406)\end{array}$ & $\begin{array}{c}-0.178 \\
(0.541)\end{array}$ \\
\hline Covariance & - & - & - & $\begin{array}{c}-0.095 \\
(0.104)\end{array}$ & $\begin{array}{c}-0.012 \\
(0.085)\end{array}$ & $\begin{array}{c}0.057 \\
(0.164)\end{array}$ & $\begin{array}{c}0.009 \\
(0.145)\end{array}$ \\
\hline \multicolumn{8}{|c|}{ Low Labor to Capital Ratio Sample } \\
\hline Tobin's $q$ & $\begin{array}{c}-0.002 \\
(0.016)\end{array}$ & - & $\begin{array}{c}-0.002 \\
(0.014)\end{array}$ & - & $\begin{array}{c}0.009 \\
(0.030)\end{array}$ & - & $\begin{array}{c}0.016 \\
(0.073)\end{array}$ \\
\hline Variance & - & $\begin{array}{r}0.0071 \\
(0.053)\end{array}$ & $\begin{array}{c}0.0011 \\
(0.054)\end{array}$ & - & - & $\begin{array}{r}-0.373 \\
(0.600)\end{array}$ & $\begin{array}{c}-0.410 \\
(0.710)\end{array}$ \\
\hline Covariance & - & - & - & $\begin{array}{c}0.030 \\
(0.045)\end{array}$ & $\begin{array}{c}0.048 \\
(0.076)\end{array}$ & $\begin{array}{c}0.221 \\
(0.325)\end{array}$ & $\begin{array}{c}0.273 \\
(0.412)\end{array}$ \\
\hline
\end{tabular}

